\title{
STUDI IMPLEMENTASI PERSEBARAN STASIUN BIKESHARE PADA LOKASI EKSISTING DI KAWASAN SCBD SENAYAN, JAKARTA
}

\author{
Angelika Fortuna Dewi Rusdy Putri ${ }^{1)}$, Liong Ju Tjung ${ }^{2)}$, Priyendiswara A.B. ${ }^{3)}$ \\ 1)Program Studi S1 PWK, Fakultas Teknik, Universitas Tarumanagara, angelikafortuna3@gmail.com \\ 2)Program Studi S1 PWK, Fakultas Teknik, Universitas Tarumanagara, jt.liong@pps.untar.ac.id \\ 3)Program Studi S1 PWK, Fakultas Teknik, Universitas Tarumanagara, priyendiswaraa@ft.untar.ac.id
}

\begin{abstract}
Abstrak
Masifnya pembangunan infrastruktur transportasi yang berbasis transit menandakan bahwa saat ini terdapat urgensi untuk menggiatkan penggunaan sustainable transportation di perkotaan, khususnya bagi kota dengan tingkat kemacetan yang tinggi seperti Jakarta. MRT dan konsep Transit Oriented Development (TOD) menjadi platform yang diharapkan untuk menjadi solusi untuk mencapai pembangunan kota yang berkelanjutan. Di Jakarta, salah satu kawasan yang ditetapkan menjadi Kawasan TOD adalah Kawasan SCBD Senayan yang memiliki 2 stasiun MRT yaitu Stasiun Istora Mandiri dan Stasiun Senayan. Kawasan SCBD Senayan yang ditetapkan berdasarkan RPJMD PT MRT Jakarta 2017 - 2022 merupakan segitiga emas Jakarta yang identik dengan distrik komersial kelas atas dan menjadi salah satu pusat bisnis terbesar di Jakarta. Meskipun merupakan kawasan yang well developed, kawasan ini belum cukup mengakomodir penggunaan transportasi yang sustainable karena tingginya penggunaan kendaraan pribadi. Untuk mendukung penggunaan transportasi berbasis transit seperti MRT dan Transjakarta di Kawasan SCBD Senayan, studi ini mengkaji desain spasial stasiun Dockless Bikeshare yang dapat menjadi bagian dalam transportasi publik dengan metode field approach untuk mendesain persebaran stasiun bikeshare pada lokasi-lokasi eksisting yang juga terintegrasi dengan titik transit di Kawasan SCBD Senayan. Desain spasial ini memberikan first to last mile solution, artinya jika pengguna transportasi umum sampai di titik transit, maka perjalanan selanjutnya dilakukan dengan menggunakan sepeda pinjam (bikeshare) untuk sampai ke tempat tujuannya.
\end{abstract}

Kata kunci: berkelanjutan; dockless bikeshare; infrastruktur; transportasi

\begin{abstract}
The massive development of transit oriented transportation indicates that there is rather an urgency to practice sustainable transportation in cities, especially in cities with severe congestion like Jakarta. MRT and Transit Oriented Development (TOD) become platforms that are hoped to be a solution in a sake of reaching the sustainable urban development. In Jakarta, one of the districts that is set to be a TOD area is Senayan SCBD Area with 2 MRT stations, which are Istora Mandiri and Senayan. Senayan SCBD area is legalized under the RPJMD of PT MRT Jakarta 2017-2022. Although the area is considered well developed, it is insufficient to accommodate the use of sustainable transportation due to high numbers of private use of motorized transportation. To support a-transit-based transportation like MRT and Transjakarta in Senayan SCBD Area, this study attempts to research how Dockless Bikeshare can potentially be a part of public transportation with field approach method to spatially design the bikeshare station in existed locations that are also integrated with public transit. The spatial design allows the first to last mile solution, so once people reach the transit, they can continue to get into their destination by using the bikeshare.
\end{abstract}

Keywords: dockless bikeshare; infrastructure; sustainable; transportation

\section{PENDAHULUAN}

Saat ini, tingginya peningkatan jumlah pengguna kendaraan bermotor, kurangnya integrasi dengan transportasi publik massal dan tidak mendukungnya sarana dan prasarana ruang publik (trotoar) bagi pejalan kaki menjadi sebagian faktor yang melatari kebutuhan untuk mengurangi dampaknya terhadap perkotaan, seperti kemacetan, pencemaran udara karena 
tingginya emisi kendaraan, pemborosan energi serta masalah aksesibilitas dan mobilitas, khususnya bagi para pengguna jalan yang tidak berkendara. (Dorina Pojani, 2015)

Masalah perkotaan tersebut menjadi permasalahan yang dialami oleh DKI Jakarta selama bertahun-tahun. Oleh karena itu, pemerintah provinsi DKI Jakarta sedang melakukan pengembangan infrastruktur transportasi terutama untuk mengurangi jumlah pengendara kendaraan bermotor, khususnya pada kawasan yang menarik banyak traffic seperti koridor Jalan Thamrin - Sudirman, Jakarta (Pransiska, 2019). Salah satu upaya tersebut adalah dengan pembangunan MRT Fase I (Bundaran HI - Lebak Bulus) sesuai dengan RPJMD PT MRT Jakarta 2017 - 2022 (Tiga Program Strategis PT MRT Jakarta di RPJMD 2017-2022, 2018).

Pada pembangunan MRT Fase I, terdapat kebijakan untuk menjadikan stasiun MRT sebagai titik transit TOD bagi kawasan sekitarnya dengan radius 500 meter. Stasiun MRT Fase I yang ditetapkan sebagai titik transit TOD terdiri dari 6 stasiun underground, yaitu Stasiun Bundaran HI, Stasiun Dukuh Atas, Stasiun Setiabudi, Stasiun Bendungan Hilir, Stasiun Istora dan Stasiun Senayan. Seiring dengan pembangunan MRT, Pemprov DKI dan PT MRT Jakarta mengeluarkan kebijakan lainnya mengenai Penataan dan Revitalisasi Trotoar sepanjang Jalan Thamrin Sudirman $( \pm 6,5 \mathrm{~km})$ untuk menunjang mobilitas pejalan kaki dan mendukung walkability ke stasiun MRT yang sudah ditetapkan. Penataan dan Revitalisasi Trotoar Thamrin - Sudirman diiringi dengan beberapa kebijakan, yang di antaranya adalah pembangunan jalur bikesharing.

Kawasan yang menjadi salah satu area yang dilayani oleh titik transit TOD MRT kebijakan penataan bikesharing adalah Kawasan SCBD Senayan. Kawasan ini dilewati 2 stasiun MRT, yaitu Stasiun Istora Mandiri dan Stasiun Senayan dengan perencanaan bikesharing pada trotoar di Jalan Jenderal Sudirman. Kawasan SCBD Senayan dikenal sebagai salah satu kawasan yang menjadi pusat bisnis terbesar di Jakarta yang cukup tinggi dalam men-generate traffic. Meskipun merupakan area yang well developed, kawasan ini belum cukup mengakomodir penggunaan transportasi yang sustainable karena tingginya penggunaan kendaraan pribadi dan belum terintegrasinya transportasi publik massal sehingga dibutuhkan alternatif moda transportasi yang dapat mengurangi penggunaan kendaraan bermotor dan meningkatkan penggunaan transportasi umum publik sesuai dengan prinsip TOD yang diterapkan di Kawasan Senayan.

Untuk mengakomodir kebutuhan tersebut, Dockless Bikeshare dilihat sebagai salah satu alternatif yang dapat dilakukan. Prinsipnya adalah penggunaan sepeda menjadi bagian dalam transportasi publik yang melayani first to last mile solution. Artinya, jika pengguna transportasi umum sampai di major transit, maka perjalanan selanjutnya dilakukan dengan menggunakan sepeda untuk sampai ke tempat/gedung tujuannya dengan jarak pendek antara $1-2 \mathrm{~km}$. Dockless Bikeshare merupakan sistem peminjaman sepeda publik yang penempatan dan perparkirannya fleksibel (tanpa station dock) dengan memanfaatkan ruang publik yang sudah tersedia, seperti trotoar atau badan jalan. Dockless bikeshare memungkinkan pengguna sepeda untuk melakukan peminjaman dan pengembalian sepeda melalui registrasi secara online yang berbasis aplikasi (smartphone). Secara teknis, Dockless Bikeshare tidak membutuhkan penambahan lebar jalan karena sistemnya yang share dengan lebar trotoar dan jalur pedestrian serta titik lokasi peminjaman dan perparkirannya dapat ditentukan secara fleksibel sesuai dengan kebutuhan dan kapasitas jumlah sepeda serta tempat parkir. Dari segi penyediaan jasa, operator Dockless Bikeshare dapat berasal dari swasta sehingga memungkinkan adanya private-public partnership, dimana hal ini memungkinkan pemerintah dan swasta bersinergi dalam regulasi, kebijakan, operasional dan evaluasi penyediaan sistem bikeshare yang berorientasi pada kepentingan publik (Deng Han, 2018).

\section{KAJIAN LITERATUR}

Studi dan desain yang dilakukan pada riset ini sebagian besar berbasis pada guidelines dari Institute of Transportion and Development Policy (ITDP). Pada bagian ini, studi literatur berperan sebagai pedoman dalam perencanaan desain persebaran stasiun bikeshare di 
Kawasan SCBD Senayan yang mengelaborasikan pengembangan prinsip penerapan bikesharing pada kawasan TOD, kriteria penempatan lokasi stasiun bikeshare, serta pendekatan desain stasiun sepeda pada area eksisting.

\section{Prinsip Penerapan Bikesharing Pada Kawasan TOD}

Secara umum terdapat 8 prinsip penerapan TOD pada suatu kawasan, di antaranya adalah walk, cycle, connect, transit, mix, densify, compact dan shift (ITDP, 2017) Penggunaan sepeda pada kawasan TOD mengacu pada interkoneksi antara titik transit dan jaringan transportasi umum yang menghubungkan berbagai zona (residensial, komersial, ruang publik, dsb). ITDP menganalisis bahwa terdapat 2 sasaran yang harus dituju dalam mengintegrasikan penggunaan sepeda pada Kawasan TOD. Yang pertama adalah bagaimana menyediakan jaringan infrastruktur bersepeda yang lengkap dan aman, lalu yang kedua tentang bagaimana menyediakan lokasi parkir penyimpanan sepeda yang aman dan cukup untuk pengguna. Dua sasaran ini bertujuan untuk memprioritaskan jaringan transportasi non kendaraan bermotor, khususnya dalam mengakses transit publik (Edmonton City of Sustainable Development and Transportation Services Departments, 2012). Berikut merupakan penjelasan lebih detail terkait dua sasaran tersebut, beserta metode pengukurannya.

Tabel 1. Sasaran dan Ukuran Mengenai Akses dan Parkir Sepeda Pada Kawasan TOD

Sasaran 1 : Penyediaan jaringan infrastruktur bersepeda yang lengkap dan aman

1. Kondisi jaringan sepeda yang aman

a. Jalan yang memiliki kecepatan berkendara $>30 \mathrm{~km} / \mathrm{jam}$, maka jalur sepeda harus terlindungi dan terpisah dari jalur kendaraan langsung

b. Jalan yang memiliki kecepatan berkendara $<30 \mathrm{~km} / \mathrm{jam}$ (atau lebih rendah), tidak perlu menggunakan jalur sepeda yang terlindungi, namun direkomendasikan untuk menggunakan marka

c. Jalan yang memprioritaskan pejalan kaki atau shared streets dengan batas kecepatan 15 $\mathrm{km} / \mathrm{jam}$ (jalur pedestrian dan sepeda tidak perlu dipisah)

d. Jalur yang diperuntukkan khusus untuk pedestrian dan pengguna sepeda

1. Metode Pengukuran

a. Mengidentifikasi segmen jalan yang tidak masuk kriteria sebagai jalur bersepeda yang aman

b. Mengidentifikasi jalur masuk gedung yang kurang aman untuk bersepeda dan jauh dari jalur yang aman

c. Mengidentifikasi segmen jalan yang menghubungkan stasiun angkutan umum

d. Mengukur jarak berjalan terjauh dari jalur sepeda

* Catatan : poin (a) dan (b) memiliki cakupan seluruh area pengembangan, poin (c) dan (d) hanya mencakup area layanan titik transit

Sasaran 2 : Menyediakan lokasi parkir penyimpanan sepeda yang aman dan cukup

Parkir Sepeda di

Pemberhentian

Angkutan Umum
1. Menyediakan fasilitas parkir yang aman dan cukup di setiap titik transit

a. Fasilitas termasuk rak outdoor dan indoor

b. Fasilitas tempat parkir berada di jarak 100 meter dari pintu masuk stasiun

2. Metode Pengukuran

a. Mengidentifikasi setiap stasiun yang berada dalam jarak 1 kilometer di area pengembangan

b. Mengidentifikasi stasiun yang belum memiliki fasilitas parkir yang aman

c. Rak sepeda disediakan dalam jarak 10 meter dari stasiun

1. Bangunan yang menyediakan fasilitas parkir yang aman dan cukup

a. Diterapkan pada bangunan yang memiliki luas lantai 


\begin{tabular}{ll}
\hline b. & $\begin{array}{l}> \\
\text { Bebas dari jalur pedestrian dan sirkulasi kendaraan dalam } \\
\text { jarak } 100 \text { meter dari pintu masuk }\end{array}$ \\
c. Menyediakan rak untuk sepeda
\end{tabular}

Sumber : ITDP - TOD Standard 3.0, 2017

\section{Kriteria Lokasi Stasiun Bikeshare}

Menurut ITDP (2018), lokasi stasiun bikeshare perlu memperhatikan aspek keamanan, kenyamanan dan berorientasi pada lokasi transit publik dengan prinsip kriteria lokasi sebagai berikut.

Lokasi stasiun

- Menentukan kepadatan stasiun bikeshare menggunakan radius (200 m; 250 m; 300 m; $400 \mathrm{~m} ; 500 \mathrm{~m}$ )

- Letak stasiun harus dekat dengan mass transit

- Letak stasiun dapat berada di bike lane eksisting dan/atau on streets yang aman dan aksesibel untuk pesepeda

- Letak stasiun dapat berada di dekat persimpangan jalan agar memudahkan dalam melakukan perjalanan multitrip

- Lokasi stasiun terletak di antara tempat-tempat yang menarik aktivitas dalam waktu yang berbeda.

- Letak stasiun tidak boleh berdekatan dengan jalur tertentu, seperti jalur kereta, jalur keluar-masuk pabrik atau area-area kosong (underused).

- Lokasi-lokasi lain yang dapat menjadi pertimbangan adalah : space pada on street parking, space yang tidak sering digunakan oleh pejalan kaki, area pada bawah flyover yang tidak penuh dengan kendaraan.

Idealnya, lokasi bikeshare mengacu pada 2 kriteria lokasi; (1) On Sidewalk, dimana harus terdapat pepohonan yang melindungi area dari panas matahari, memiliki jarak minimal 2 meter dari clear walking space, dekat dengan intersections, dekat dengan titik transit transportasi massal, memiliki high visibility dan pencahayaan yang baik, kemudahan akses bagi pengguna dan dekat dengan sarana-prasarana sepeda. (2) On street, yaitu dekat dengan intersections, dekat dengan titik transit transportasi massal, memiliki high visibility dan pencahayaan yang baik, volume kendaraan dan kecepatan tempuh yang rendah, dekat dengan sarana-prasarana sepeda dan tidak menghalangi drainase. Titik parkir yang disarankan harus memenuhi target kepadatan, keterhubungan dengan titik transit, mendukung zona aman bersepeda, terletak pada mixed use area termasuk zona perkantoran, serta menghindari physical barriers seperti gated area dan pembatas infrastruktur.

\section{Besaran Stasiun}

Setelah lokasi stasiun sudah ditentukan, selanjutnya adalah menentukan seberapa besar stasiun yang ingin didesain. Pertimbangan tersebut meliputi jumlah sepeda dan area parkir. Untuk menentukan besaran stasiun, dapat dilakukan cara-cara seperti berikut.

- Melakukan survey untuk melihat pergerakan orang untuk melihat kemungkinan perjalanan tersebut dapat dicapai dengan menggunakan sepeda.

- Melihat titik-titik attraction/titik-titik keramaian yang dapat menciptakan demand yang lebih besar. 
- Kapasitas sepeda per stasiun dihitung berdasarkan standar 1000 : 10-30. Artinya setiap 1000 penduduk, diperlukan 10-30 sepeda tergantung dari kebutuhan.

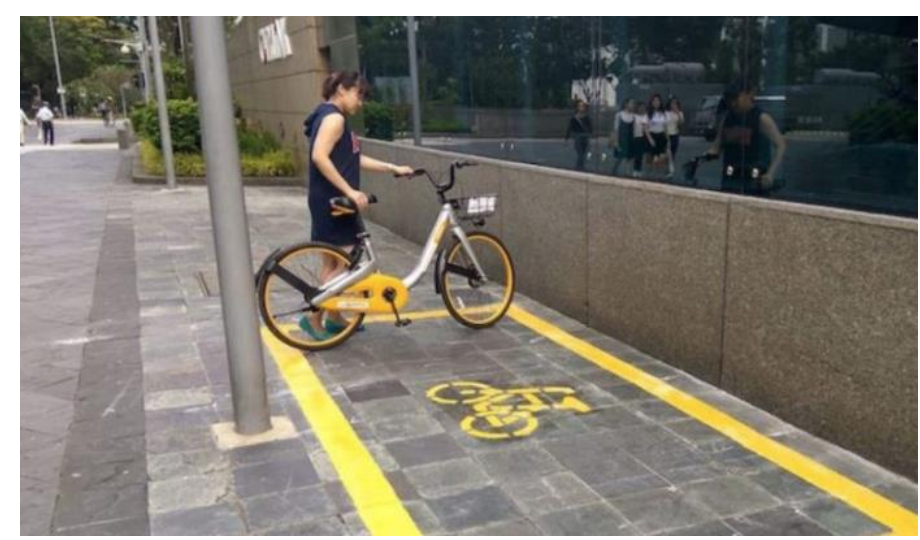

Gambar 1. Stasiun Dockless Bikeshare Sumber : Alta Planning, 2018

Untuk penerapan Dockless Bikeshare, bike parking areas yang merupakan area parkir sepeda khusus ditentukan luasannya berdasarkan pembatas garis, serta penempatannya lebih fleksibel sesuai kapasitas ruang publik yang tersedia.

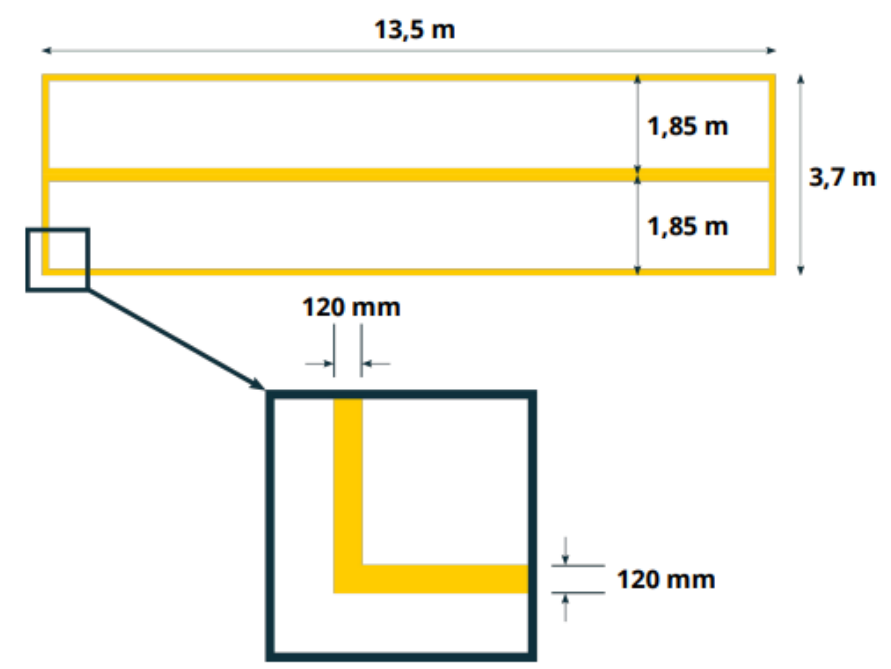

Gambar 2. Lebar marka stasiun Dockless Bikeshare Sumber : Rancangan Uji Coba Bikeshare ITDP, 2018

\section{Desain Stasiun Bikeshare}

Penentuan seberapa besar stasiun menentukan ukuran desain yang akan diimplementasikan. Dengan ukuran standar minimal 2,0 x 1,0 meter atau 1,85 x 0,8 meter untuk setiap kebutuhan parkir sepeda, dapat ditentukan berbagai model stasiun bikeshare yang dapat menjadi alternatif. Meskipun standar desain ukuran stasiun bikeshare di setiap negara berbeda-beda, seperti pada beberapa kota di Kanada dan Eropa yang menggunakan standar 2,0 × 2,0 meter atau 2,0 × 2,5 meter, namun untuk standar ukuran Indonesia, ITDP Indonesia menentukan ukuran standar sebagai pedoman seperti berikut. 


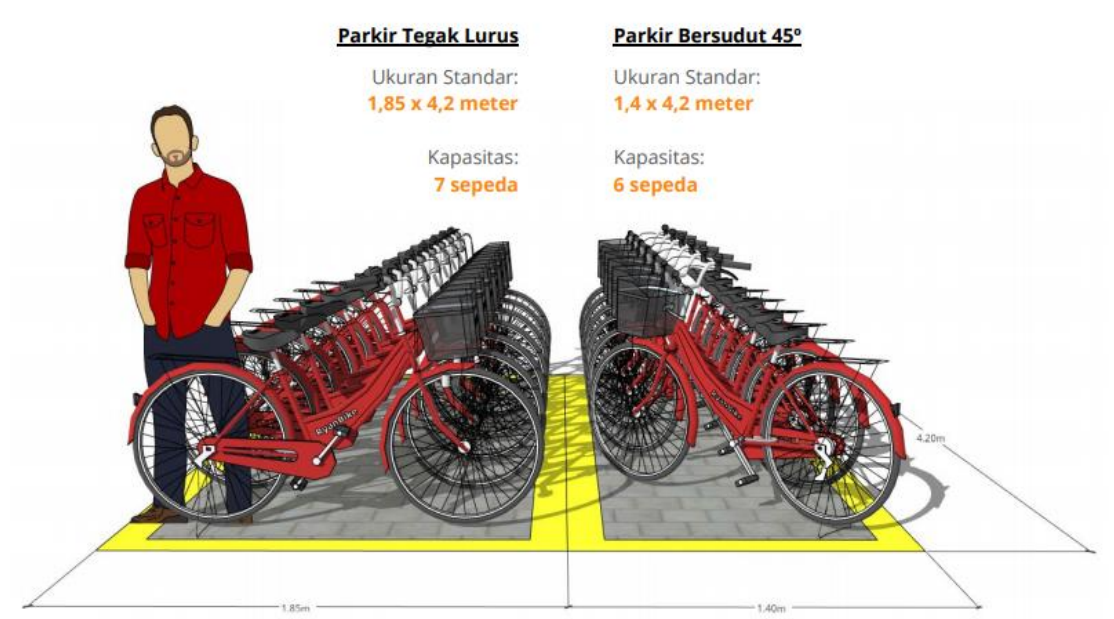

Gambar 3. Ukuran Stasiun Berkapasitas 6-7 Sepeda Sumber : Rancangan Uji Coba Bikeshare ITDP, 2018

Untuk kapasitas 6-7 sepeda dibutuhkan space sekitar 7,77 $\mathrm{m}^{2}(1,85 \times 4,2 \mathrm{~m})$ dan 5,88 $\mathrm{m}^{2}$ $(1,4 \times 4,2 \mathrm{~m})$. Untuk lebar space yang terbatas, dapat menggunakan alternatif $5,88 \mathrm{~m}^{2}(1,4 \times$ $4,2 \mathrm{~m}$ ) dengan sudut parkir 45ㅇ karena lebar yang dibutuhkan lebih sedikit daripada ukuran space pertama, yaitu 1,4 meter.

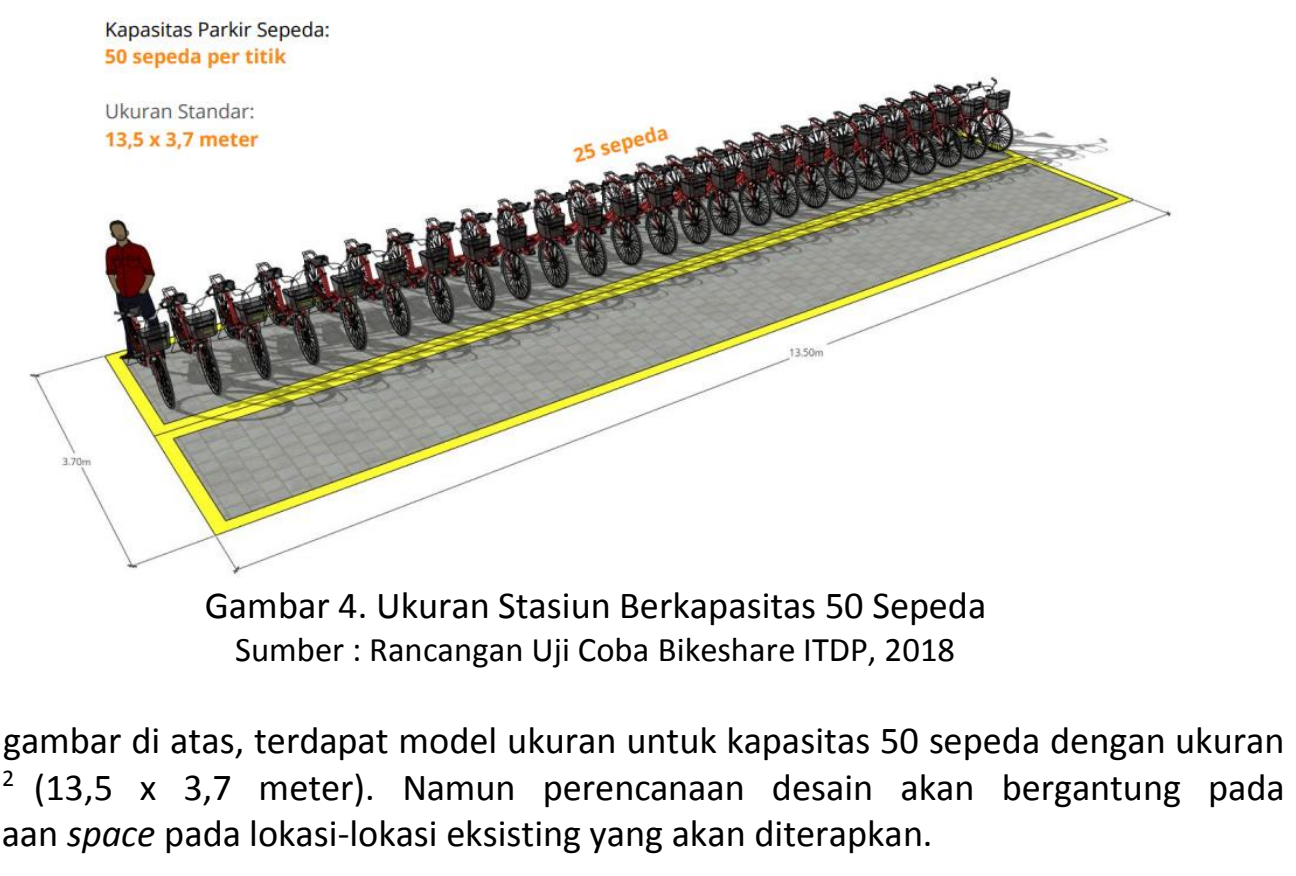

\section{METODE}

Studi ini menggunakan beberapa analisis, di antaranya adalah analisis lokasi, analisis jaringan transportasi umum dan analisis spatial design. Studi ini menganalisis kondisi lapangan yang potensial menjadi lokasi stasiun bikeshare, atau yang disebut dengan metode field approach. Dalam menentukan titik bikeshare, terlebih dahulu diketahui lokasi titik transit, akses masuk/keluar MRT dan Transjakarta, beserta radius pelayanannya, kemudian dilakukan field approach untuk diketahui lokasi yang potensial untuk dijadikan stasiun bikeshare. 


\section{DISKUSI DAN HASIL}

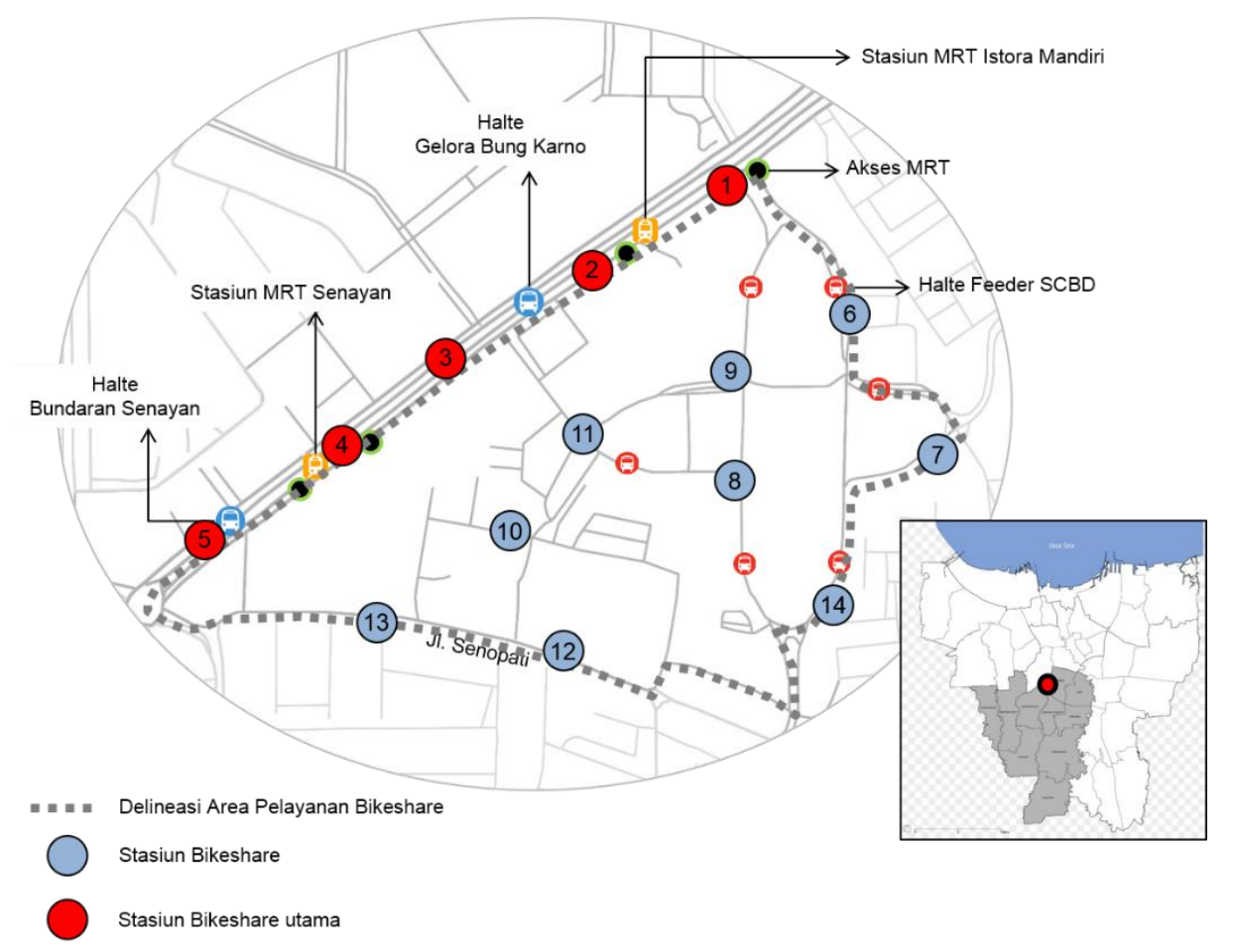

Gambar 5. Persebaran Titik Stasiun Bikeshare di Kawasan SCBD Senayan Sumber: Penulis, 2019

Secara administratif, delineasi area pelayanan bikeshare berada di Kelurahan Senayan, Kebayoran Baru, Jakarta Selatan. Delineasi ini memiliki luas sebesar \pm 66 hektar. Melalui metode field approach, dianalisis bahwa terdapat 14 lokasi eksisting yang memungkinkan untuk dijadikan stasiun bikeshare di Kawasan SCBD Senayan. Terdapat 5 stasiun bikeshare utama yang terletak di trotoar Jl. Jendral Sudirman dan terletak dekat dengan akses MRT dan Transjakarta. Stasiun bikeshare reguler berjumlah 9 yang tersebar di seluruh area yang meliputi komersial perkantoran, pusat perbelanjaan, apartemen dan entertainment spot.

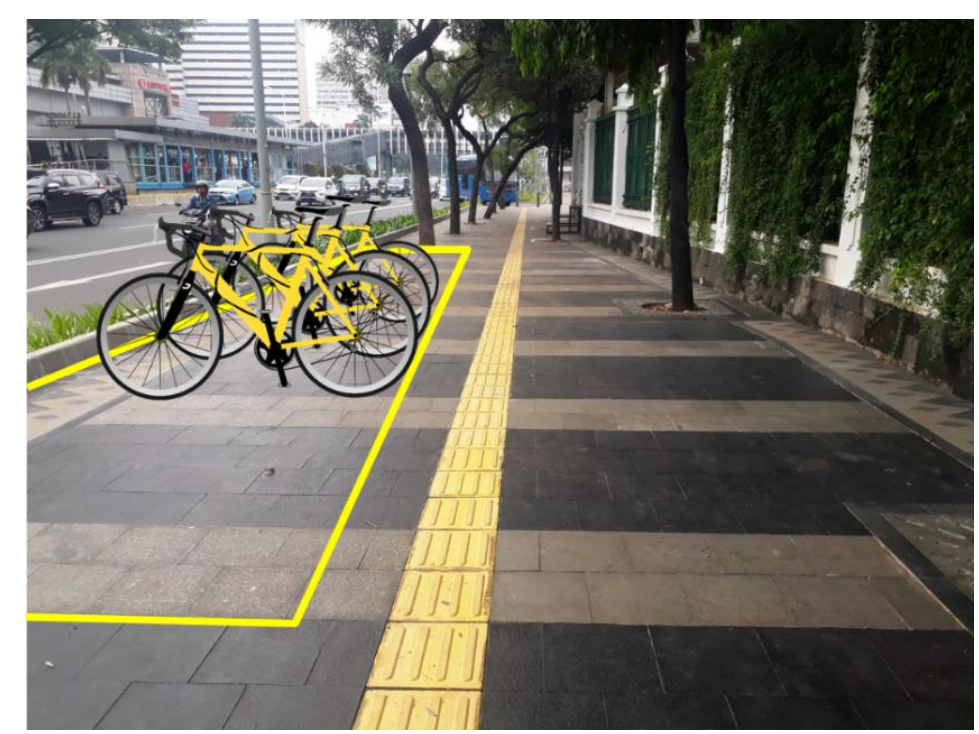

Gambar 6. Ilustrasi desain stasiun Dockless Bikeshare Sumber: Penulis, 2019 
Tabel 2. Desain Stasiun Dockless Bikeshare Pada Lokasi Eksisting di Kawasan SCBD Senayan

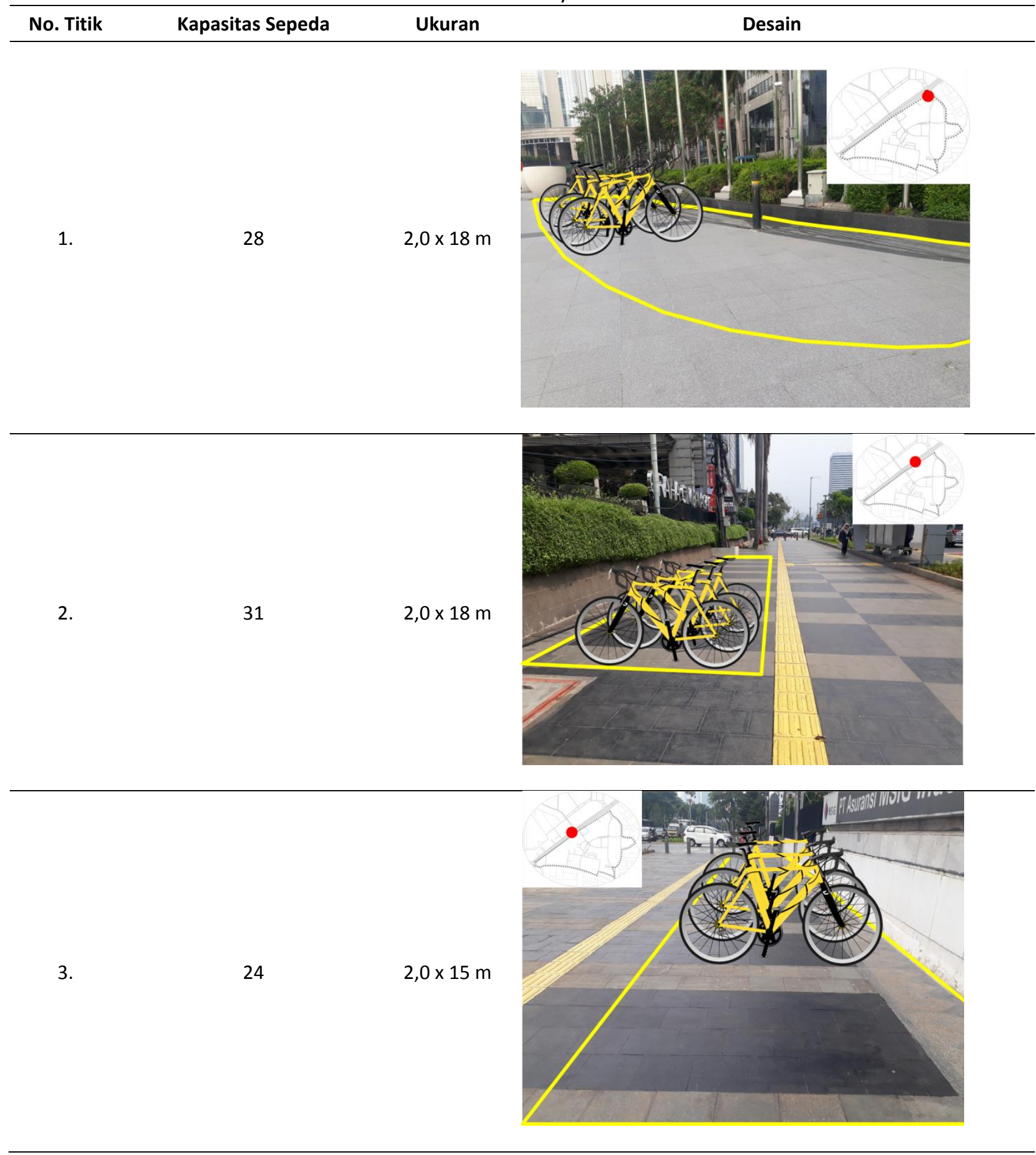




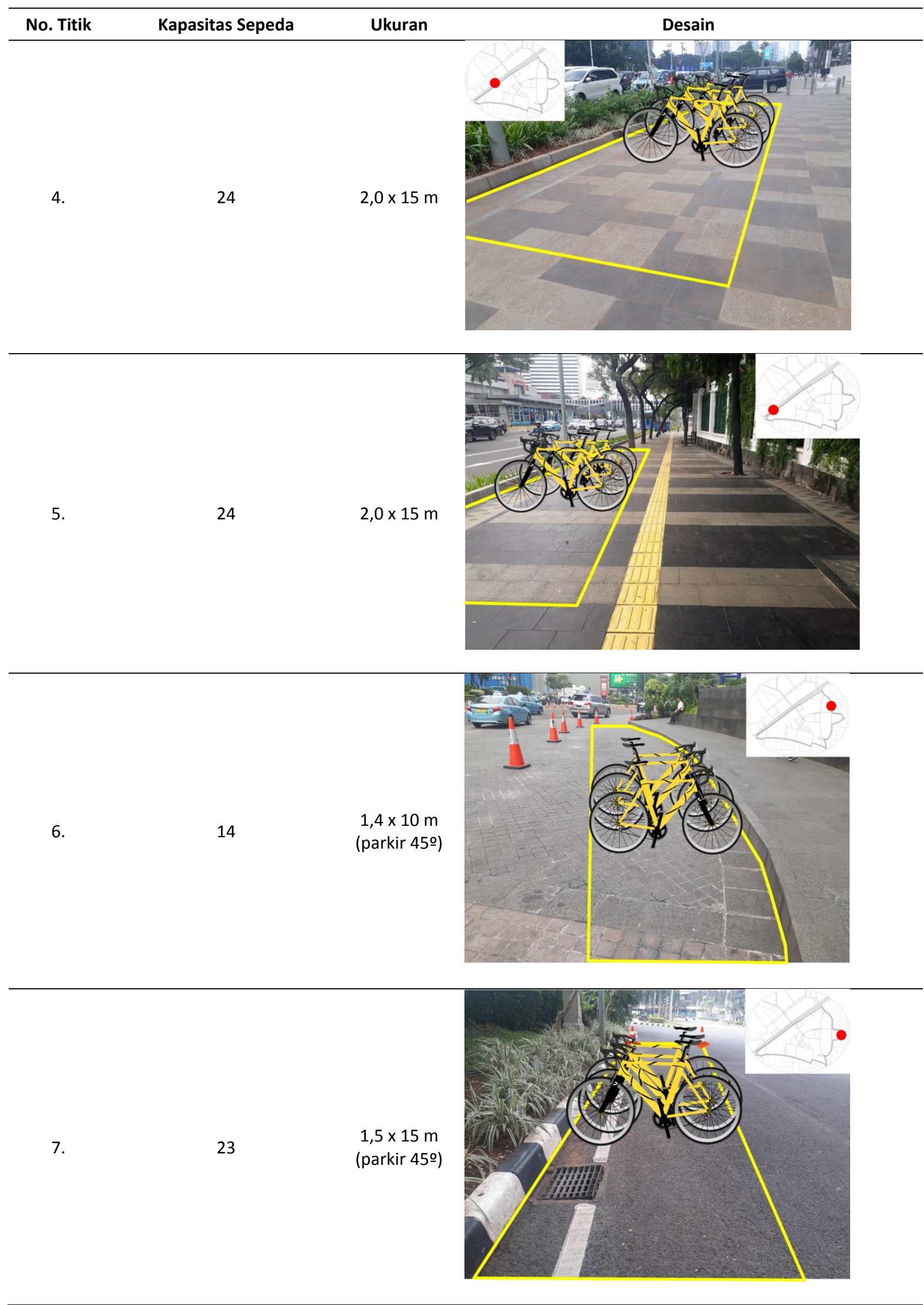




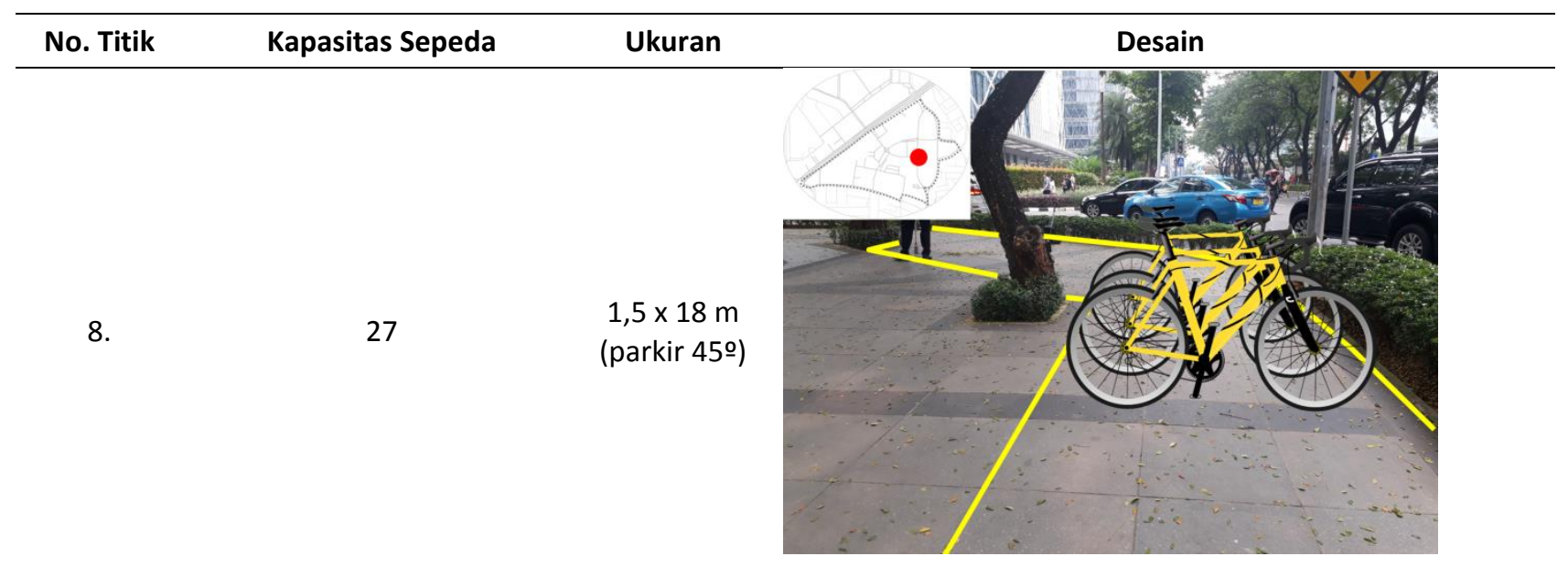

10.
$1,5 \times 7,0 \mathrm{~m}$ (parkir 45ㅇ)
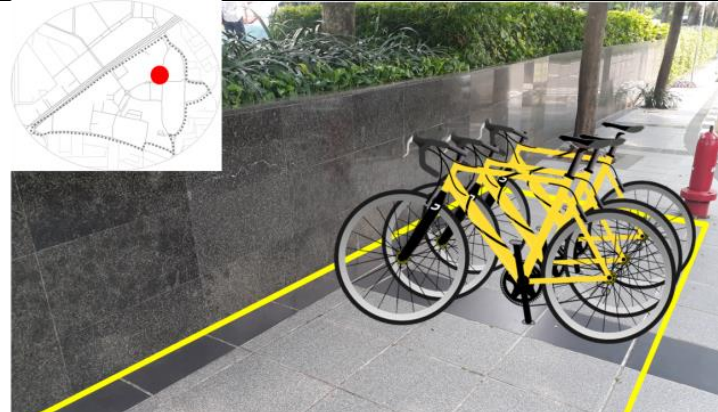

$1,5 \times 7,0 \mathrm{~m}$ (parkir 45ㅇ)

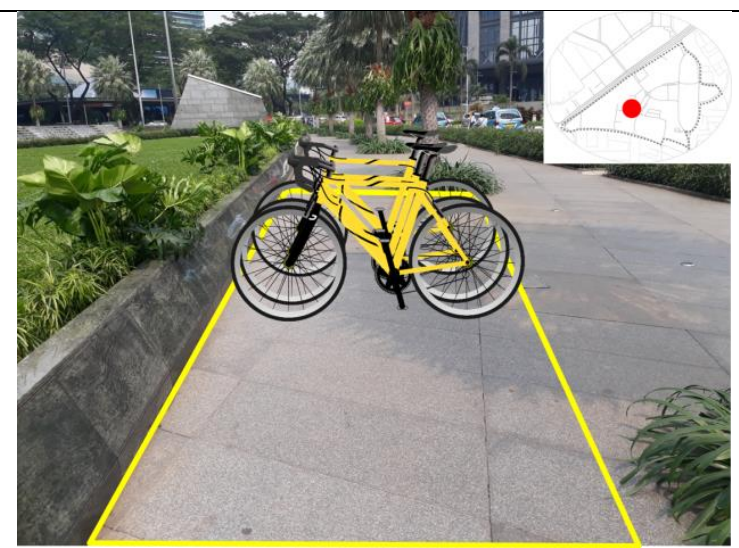

11.

11
$1,5 \times 7,0 \mathrm{~m}$ (parkir 45ㅇ)

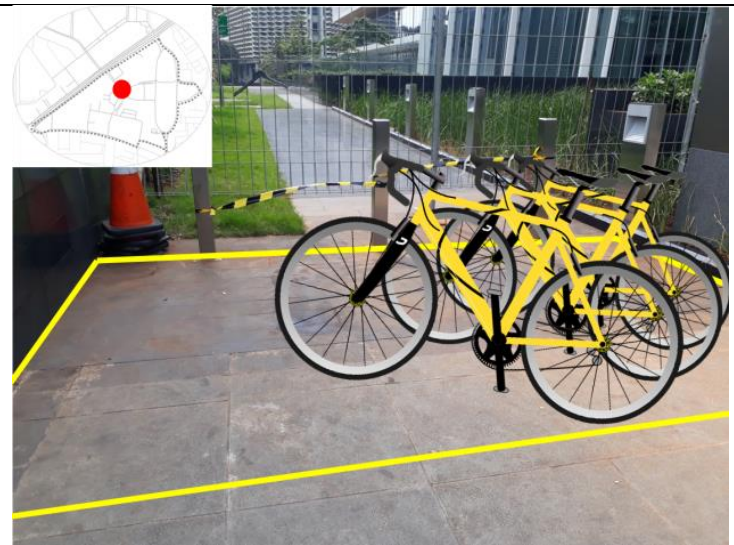




\begin{tabular}{|c|c|c|c|}
\hline No. Titik & Kapasitas Sepeda & Ukuran & Desain \\
\hline 12. & 15 & $2,0 \times 10 \mathrm{~m}$ & \\
\hline 13. & 12 & $\begin{array}{l}1,5 \times 8,0 \mathrm{~m} \\
\text { (parkir 45) }\end{array}$ & \\
\hline 14. & 15 & $2,0 \times 10$ & \\
\hline Total & 270 & & \\
\hline
\end{tabular}

Desain ini akan menyediakan kapasitas total parkir sebanyak 270 sepeda. Namun berdasarkan standar dari ITDP, terdapat rasio antara jumlah sepeda dengan kapasitas total parkir sebanyak $1: 2$. Artinya jika kapasitas total parkir adalah 270 , maka jumlah sepeda yang harus disediakan adalah 135.

Tabel 3. Bike System Size di Kawasan SCBD Senayan

\begin{tabular}{l}
\hline Jumlah sepeda : 135 \\
\hline Kapasitas parkir total : 270 \\
\hline Jumlah stasiun : 14 \\
\hline Kapasitas sepeda/stasiun : 10 - 31 \\
\hline Jarak antar parkir : $\leq 150 \mathrm{~m}$ \\
\hline Luas parkir per sepeda: \\
$-1,40 \times 0,7 \mathrm{~m}=0,98 \mathrm{~m}^{2}$ (untuk space terbatas) \\
$-\quad 1,85 \times 0,7 \mathrm{~m}=1,3 \mathrm{~m}^{2}$ \\
\hline Radius : 300 meter \\
\hline Lokasi stasiun utama : \\
Lokasi stasiun utama hanya berada sharing dengan jalur pedestrian di Jl. Jend. Sudirman, dekat \\
dengan akses MRT dan Transjakarta. \\
\hline Area yang tidak ter-cover radius : \\
Sebagian kecil area komersial dan campuran \\
Sumber: Penulis, 2019
\end{tabular}




\section{KESIMPULAN DAN SARAN}

Dari hasil analisis tersebut dapat disimpulkan bahwa implementasi eksisting persebaran spasial stasiun bikeshare dapat dilakukan di Kawasan SCBD Senayan, namun masih dalam jumlah yang terbatas mengingat tingginya aktivitas di kawasan tersebut. Hal-hal yang perlu ditingkatkan agar mendukungnya sepeda sebagai sustainable transportation di Kawasan SCBD Senayan di antaranya adalah ;

a.) Bagi Pemerintah

- Pemerintah dapat merevisi kembali regulasi dan kebijakan bersepeda di Jakartayang melingkupi sarana dan prasarana, perilaku dan budaya bersepeda, serta keselamatan pesepeda, serta sistem transportasi umum yang terintegrasi dengan sepeda.

- Pemerintah dapat menerapkan kebijakan insentif bagi pihak swasta yang mendukung adanya bikeshare di Kawasan Senayan. Misalnya bagi pemilik gedung/properti untuk menyediakan fasilitas parkir sepeda gratis. Insentif dapat berupa pengurangan pajak bangunan, dsb.

- Pemerintah dapat menyediakan/meningkatkan/memperbaiki infrastruktur berupa jalur sepeda (rencana/eksisting), aspek landscape (pohon/penghijauan, desain penataan jalan) dan pelebaran trotoar untuk shared biketrack agar menciptakan kenyamanan bersepeda yang aman.

- Pemerintah dapat berkoordinasi dengan pihak swasta, akademisi dan organisasi nonpemerintah untuk menciptakan policy framework terkait Dockless Bikeshare, menciptakan private-public partnership agar dapat mewujudkan konsep Dockless Bikeshare yang masih belum familiar bagi pemerintah.

b.) Bagi pihak swasta

- Pihak swasta dapat membantu menyediakan space untuk parkir sepeda dan fasilitas penunjangnya.

- Pihak swasta dapat menyediakan program CSR yang mendukung adanya bikeshare.

c.) Bagi operator

- Operator Dockless Bikeshare di Indonesia, seperti GOWES dapat bekerja sama dalam skema private-public partnership untuk mewujudkan implementasinya, seperti membantu pemerintah dalam analisis tracking yang terintegrasi dengan platform Jakarta Smart City.

- Operator dapat mensosialisasikan penggunaan Dockless Bikeshare yang melibatkan teknologi aplikasi di smartphone yang masih belum familiar pada masyarakat.

d) Bagi komunitas pesepeda

- Komunitas pesepeda dapat membantu mengampanyekan sepeda sebagai sustainable transportation yang murah dan ramah lingkungan.

- Komunitas dapat bekerja sama dengan berbagai pihak untuk menyelenggarakan community approach berupa workshop, seminar, bike field trip dan acara fun bike untuk mengedukasi masyarakat mengenai manfaat fisik dan psikis dalam bersepeda sehingga dapat menarik minat masyarakat sekaligus mengenalkan konsep Dockless Bikeshare secara lebih luas.

\section{REFERENSI}

Dana Y., J. M. (2018). The Bikeshare Planning Guide. New York: Institute of Transportation and Development Policy.

Deng H. L. S. (2018). Can Private and Public Bike-Share Coexist? A Cautionary Tale from China. Sustainable Transport - ITDP China, 1-2.

Dorina P. D. S. (2015). Sustainable Urban Transport in the Developing World: Beyond Megacities. MDPI Sustainability, 1-3. 
Edmonton, C. o. (2012). Transit Oriented Development Guidelines. Edmonton: Edmonton City Council.

Indonesia, I. (2018). RAPAT FINALISASI Uji Coba Bike Share di Kota Jakarta. Central Jakarta, DKI Jakarta, Indonesia: Institute of Transportation and Development Policy.

Jakarta, B. D. (2018, July 12). RPJMD DKI Jakarta 2017-2022. Diambil kembali dari https://bappeda.jakarta.go.id

Kenyon, A. (2017). TOD Standard 3.0. New York: Institute of Transportation and Development Policy.

Pransiska, L. (2019, June 14). Kompas. Diambil kembali dari otomotif.kompas.com: https://otomotif.kompas.com/read/2019/06/14/100200815/pemerhati-transportasiperlu-pembatasan-motor-di-sudirman-thamrin

Tiga Program Strategis PT MRT Jakarta di RPJMD 2017-2022. (2018, 4 5). Diambil kembali dari jakartamrt.co.id: https://www.jakartamrt.co.id/2018/04/05/tiga-program-strategis-ptmrt-jakarta-di-rpjmd-2017-2022/ 
